\title{
Sea warming affects bream (Sparus aurata) tissues and stress proteins (HSP70)
}

\author{
D. Madeira*, C. Vinagre***, R. Rosa**, P.M. Costa****, M.H. Costa****, S. Caeiro****, M. Galésio*, H.M. \\ Santos $* * * * * *, * * * * * *$, C. Nuñez $* * * * * *$, E. Oliveira*****, L. Castro****, I. Peres****, C. Lodeiro******, J.L. \\ Capelo****** and M.S. Diniz*
}

*REQUIMTE, Departamento de Química, Faculdade de Ciências e Tecnologia, Centro de Química Fina e Biotecnologia, Universidade Nova de Lisboa, 2829-516 Caparica.

**Laboratório Marítimo da Guia, Centro de Oceanografia, Faculdade de Ciências da Universidade de Lisboa, Av. Nossa Senhora do Cabo, 939, 2750-374 Cascais, Portugal

***Centro de Oceanografia, Faculdade de Ciências, Universidade de Lisboa, Campo Grande, 1749-016 Lisboa, Portugal

****IMAR-Instituto do Mar, Faculdade de Ciências e Tecnologia, Universidade Nova de Lisboa -Departamento de Ciências e Engenharia do Ambiente. Quinta da Torre, 2829-516 Caparica, Portugal.

*****BIOSCOPE Group, Physical-Chemistry Department, Faculty of Science, Campus Ourense, University of Vigo, 32004, Ourense, Spain.

******Unitat d'Enginyeria de Proteines i Proteomica, Institut de Biotecnologia i Biomedicina, Universitat Autònoma de 08193, Barcelona, Spain

The increase in $\mathrm{CO}_{2}$ emissions from anthropogenic sources may not only result in temperature increase on a global scale but also in increased ocean acidification (OA), by lowering the ocean's capacity to absorb additional atmospheric $\mathrm{CO}_{2}$. As a consequence, changes in ocean chemistry are prone to occur through the imbalancing of sea-atmosphere $[1,2]$ gas exchange, thus affecting $\mathrm{O}_{2}$ absorption as well.

There are many studies on the potential effects of OA and increased ocean temperatures on the physiology of marine organisms but little is known about changes at histological level and there are still several gaps at molecular level which must be studied for a better understanding of all biological mechanisms involved. With regard to hypoxia, alterations to the stress response can provide information on the organisms' physiological effects and coping strategies triggered by anoxia. For instance, it is known that organisms respond by reducing protein synthesis $[3,4]$. Once temperature affects physiological, behavioral and ecological processes, there is a need to understand what mechanisms are behind the organisms' response to stress, enhancing our predictive and environmental management capacities considering a climate change scenario. This is of great importance, in particular to countries with a sea-based economy.

The aim of the present study is to assess the stress response of a marine fish, sea bream (Sparus aurata) exposed to increasing water temperature and different water acidity (alone or in combination). Here we present preliminary data on temperature effects on $S$. aurata at a cellular and molecular level. In addition, tissue samples from muscle, livers, gills and intestine are examined to evaluate any alterations caused by altering this physical parameter.

Fish were distributed randomly in tanks $(n=96)$ and allowed to acclimate at $18^{\circ} \mathrm{C}$ (the same temperature of the hatchery) before the beginning of the bioassays. After assessment of the upper thermal limits (UPL), water temperature was increased at a rate of $1^{\circ} \mathrm{C}$ per hour using a thermostatized bath with a constant rate of watertemperature until reaching the endpoint, following the dynamic method of Critical Thermal Maximum (CTM) [5]. Every $2^{\circ} \mathrm{C}$ step, fish were euthanized by cervical transection and the selected organs removed and stored at $80^{\circ} \mathrm{C}$ until further analysis. Sub-samples were taken and processed for histological examination following standard techniques [6]. Frozen samples were analysed for heat stress proteins (HSP70) as described by Madeira et al. [7]. The histological observations were carried out using a Leica microscope (DMLB model). Preliminary results of the histological examination showed changes in the cellular structure, with visible damage at higher 
temperatures in liver and gills (Fig. 1). Regarding HSP70, significant changes were observed throughout the temperature assay. The results indicate that elevated water temperature can be a major stressor that will affect fish due to potential climate changes, thus compelling the need to perform these studies to enhance our predictive and environmental management capacities.

\section{References}

1. IPCC, Climate change, Cambridge: Cambridge University Press: 1000pp., 2007.

2. Feeley R.A. et al., Science, 305:362-366, 2004.

3. Hoffman G.E. et al., Annu. Rev. Ecol. Evol. Syst., 41:127-147, 2010.

4. Tomanek L., Annu. Rev. Mar. Sci., 3:373-399, 2011.

5. Mora C. and Ospina A., Mar. Biol., 139: 765-769, 2001.

6. Martoja R. and Martoja-Pierson M., Initiation aux Techniques de L'Histologie Animal, Paris: Masson: 345pp., 1967.

7. Madeira D. et al., Cell Stress and Chaperones, 17:707-716, 2012.

The authors acknowledge the funding by Fundação para a Ciência e Tecnologia through grant PTDC/MAR/119068/2010 and through project no. PEst-C/EQB/LA0006/2011 granted to Requimte.

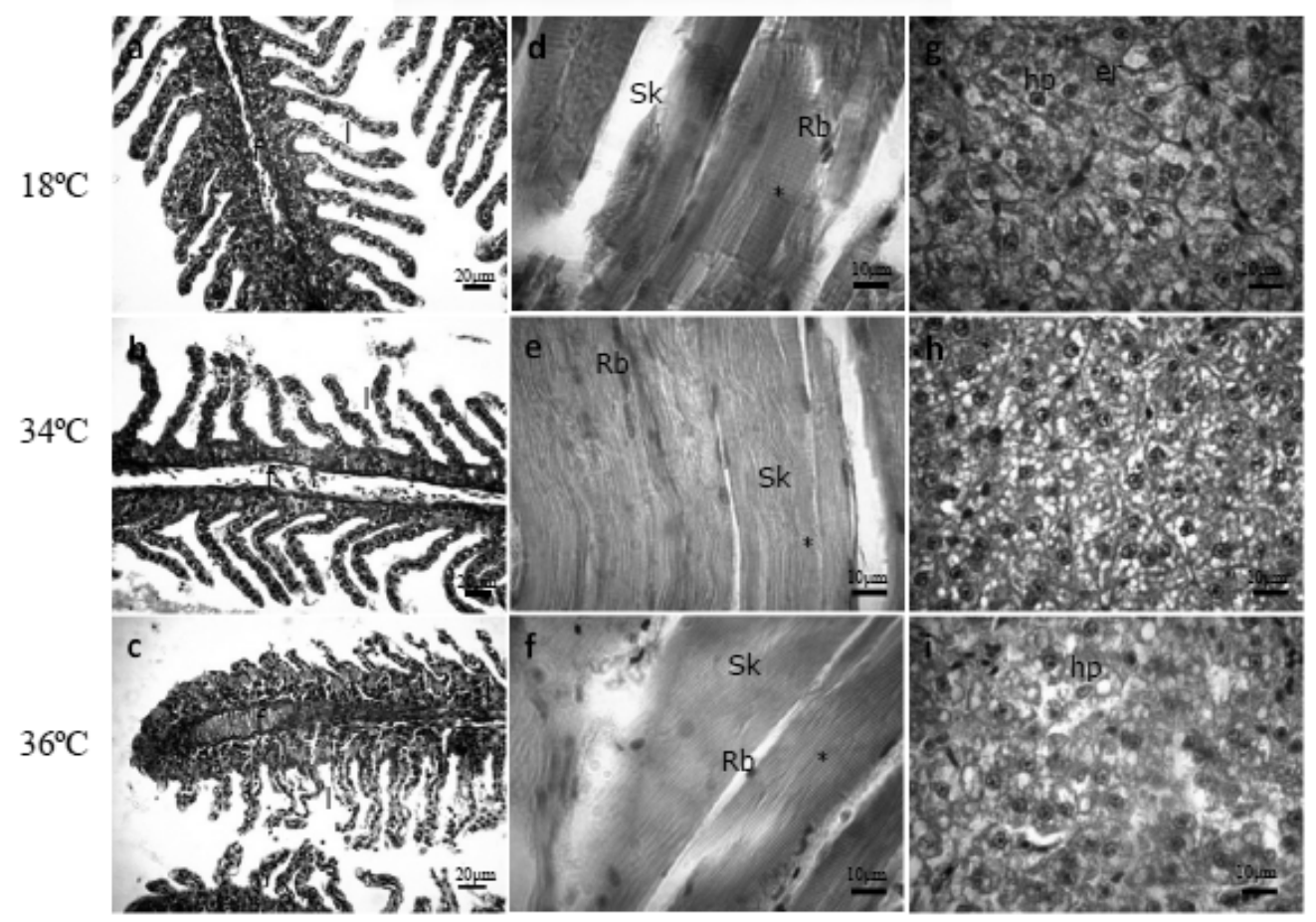

Figure 1. Representative images from sea bream gills (a to c), muscle fibers (d to f), liver (g to i) exposed to increasing temperatures. Legend: Gills - f, filament; 1, lamellae. Muscle fibers - Sk, skeletal muscle; crossstriations $(*)$; Rhabdomyopcytes $(\mathrm{Rb})$. Liver—hp, hepatocytes; er, eritrocytes. Staining: H\&E. 